\title{
39
}

\section{ECOGRAI - A method to design and to implement Performance Measurement Systems for industrial organizations - Concepts and application to the Maintenance function}

\author{
G. Doumeingts a, F. Clave a and Y. Ducq a
}

a GRAI/LAP - Université Bordeaux 1 - 351 Cours de la Libération 33405

Talence cedex - FRANCE -Tel 56846530

\begin{abstract}
:
ECOGRAI is a method to design and to implement Performance Indicator Systems (PIS) for industrial organizations. Based on the GRAI model, it can be applied on all the production functions (Engineering, Manufacturing, Quality, Maintenance, delivery...) with a global approach or more specifically on only one function. The results of the PIS design is a coherent set of specification sheets describing each Performance Indicator. The implementation and the operating of this system is supported by an EIS (Executive Information System) tool.

This paper is presenting first the main characteristics of the ECOGRAI method, the six phases of its structured approach, the various actors involved and the ECOGRAI implementation. The second part shows an example of application to one production function : the Maintenance function.
\end{abstract}

\section{Key words :}

Performance Indicators, method, modelling, structured approach, maintenance, EIS

\section{INTRODUCTION}

The industrial performance measurement is today one of the basic tools for the production unit control. This performance measurement becomes more and more important because it is used in the "Benchmarking" approaches and in the "Self Auditing Procedure".

Based on the GRAI method users request, the GRAI Group has been working on this domain since 1988. Indeed, the GRAI method allows to elaborate specifications in order to choose or to develop Production Management Systems. But when the system is chosen and implemented, the user wants to know its performance. It is why ECOGRAI method was developed.

ECOGRAI is a method to design and to implement Performance Indicator Systems (PIS) for industrial organizations and used by the decision makers of 
the Production Management Systems to measure the achievement of their objectives. The results of the PIS design is a coherent set of specification sheets describing each Performance Indicator (indicators, concerned actors, required information and processing...). The implementation and the operating of the PIS is supported by an EIS (Executive Information System) tool.

First, the various phases and the various actors involved in the ECOGRAI structured approach are presented. In a second part, an example of application on one function of the production system, the Maintenance function, will be described.

\section{THE ECOGRAI METHOD}

The main characteristics of the ECOGRAI method are :

- a logical process of analysis / design using a top-down approach, and allowing to decompose the objectives of the strategic levels into objectives for operational levels,

- a concrete process of participative implementation, creating a dialogue between the various levels of the hierarchy, and favouring the identification of indicators by the future users involved in the study : it is a bottom up implementation,

- the use of a number of tools and graphical supports : GRAI grids, GRAI nets, splitting up diagrams, coherence panels, specification sheets,

- the search of a limited number of Performance Indicators by an original approach (figure 1) : identification of the objectives assigned to the decision makers (target situations which have to be reached inside the functions, depending on the management level which are considered), identification of the variables on which the decision makers can act to reach their objectives (we can call these variables "Decision Variables" or "Drivers"), and identification of the Performance Indicators, quantified data which measure the efficiency of an activity or a set of activities of a function in the process to reach the objectives. The originality of the ECOGRAI method is not defining the Performance Indicators, but the search of Decision Variables or Drivers on which decision makers can act to reach their objectives. The Performance Indicator is a consequence of the preliminary choice,

- a coherent distribution of Performance Indicators covering the various functions and the various decision levels (strategic / tactical / operational).

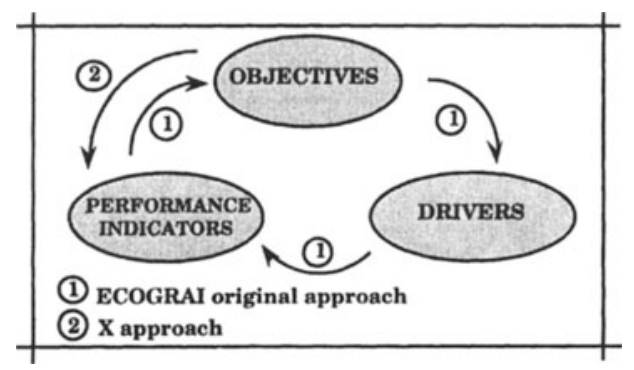

Figure 1. The ECOGRAI original approach 


\subsection{The six phases of ECOGRAI method}

The logical structured approach of the method is decomposed into six phases (figure 2). The first phase (phase 0) consists in analysing the Production Management System and in determining in which decision centers the Performance Indicators will be defined. The two following phases (phase 1 and 2) aim at identifying the basic elements which are required : the objectives and the drivers. The fourth phase (phase 3 ) consists in identifying the Performance Indicators, the fifth (phase 4) in designing the information system of the Performance Indicators, and the sixth (phase 5) in implementing it on the Production Management Information System.

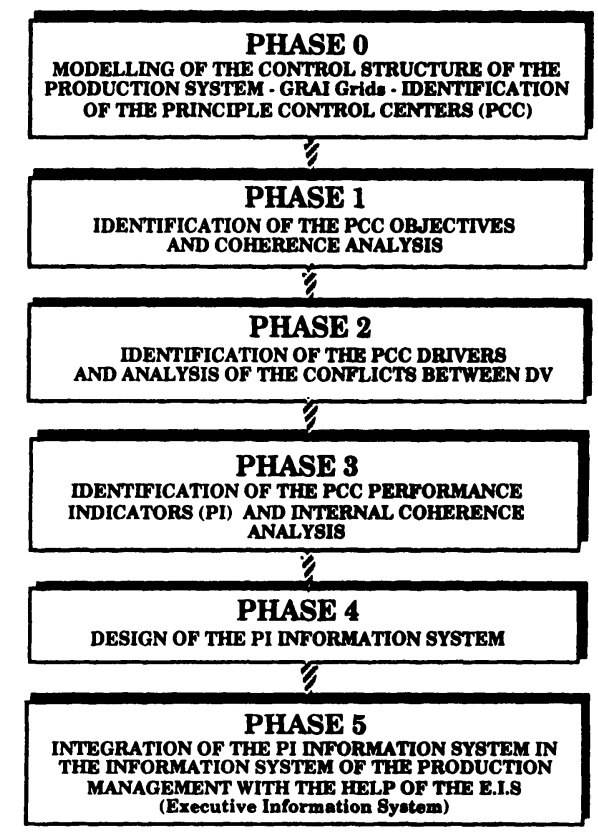

Figure 2. The six phases of the structured approach

\subsubsection{Phase 0 : Modelling of the Production System Control Structure and Identification of the PCC \\ The objective of this phase is to determine the Principal Control Centers of the Production Management System in which the Performance Indicators will be designed.}

Phase 0.1-Modelling of the Production System Control Structure. As written above, ECOGRAI uses the GRAI tools (grids and nets) to model the Production System control structure in order to identify the set of the decision centers, their activities, their links (decisional and informational) and the basic elements which are taking into account to design a Performance Indicator : the objectives and the drivers. 
This paper is not aiming at describing the GRAI method. Therefore, for a better understanding of ECOGRAI, a short description of the GRAI tools used (the grid and the nets) is presented below.

The GRAI grid takes up the hierarchical and functional approach. It allows to identify the set of decision centers of the studied system, as well as their links.

The GRAI grid is presented in the form of a matrix :

- the managerial axis or control axis which represents the various levels of decision which can be found in a Production System. Traditionally, this axis is decomposed hierarchically in several levels, according to the nature of the decisions : strategic, tactical, and operational levels.

- the production axis which describes the various activities required to the product life cycle. It is decomposed into several functions which group a set of activities having a same identified finality (Engineering, Manufacturing, Quality, Maintenance, Delivery, Recycling...).

Each function of this axis is decomposed in : to manage the products (internal or external, it means supplying and purchasing), to manage the resources (human or technical) and to plan (to synchronize at each level product and resource management).

A decision center is defined by a function and decision level cross.

The GRAI nets are aiming at describing in details all the activities identified inside each decision center of the GRAI grid.

Then, in this phase, the production system control structure studied is modelled with a global GRAI grid (all the functions). It is split up into specific GRAI grid by function (figure 3 ).

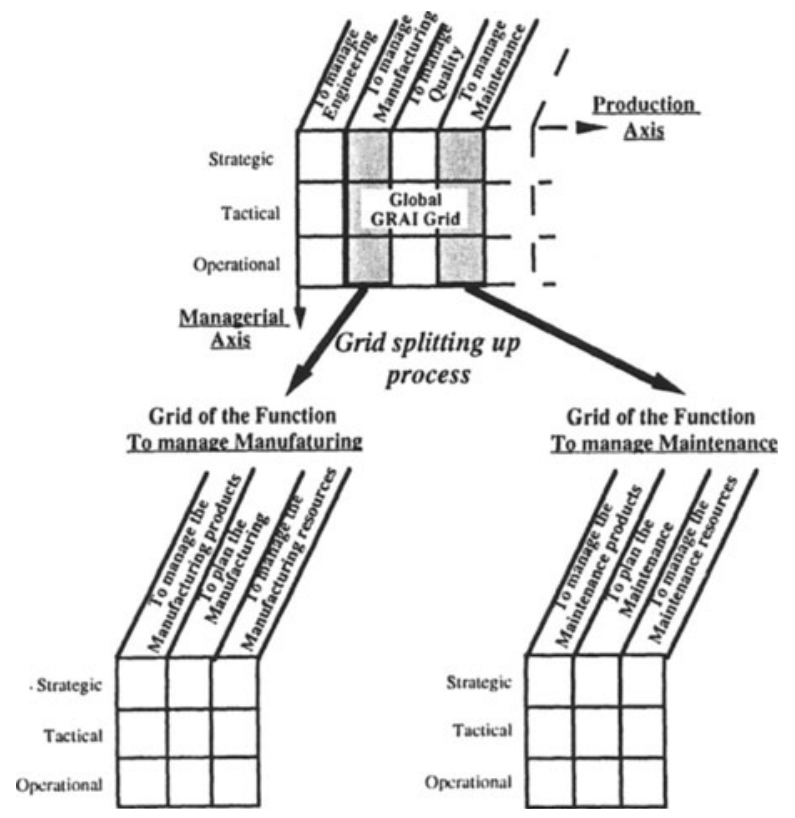

Figure 3. Global Grid split up into various grids for each function of the Production Axis 
Phase 0.2-Identification of the Principal Control Centers (PCC)

The objective of this phase is to "scrutinize" the grids in order to determine the Principal Control Centers. By definition, they are the decision centers which have, as a consequence of their activity, a principal influence on the system control. We search a set of PCC allowing to cover the various functions of all the grids and the various decisionnal levels (figure 4).

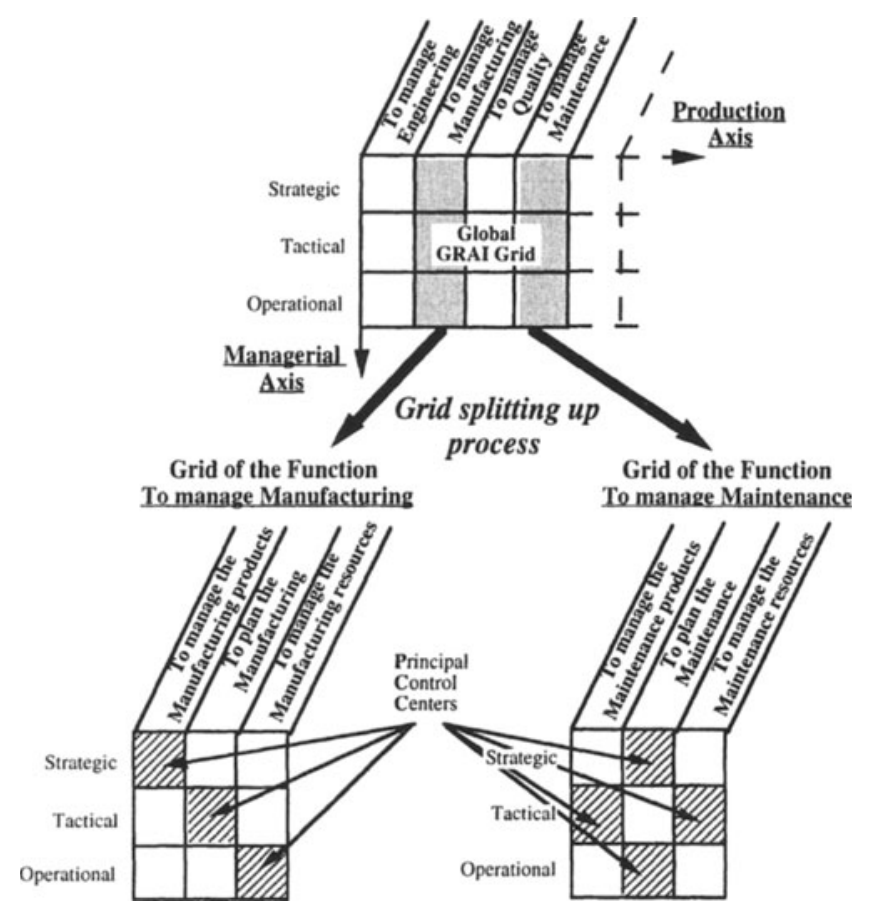

Figure 4. Phase 0 results - Identification of the Principal Control Centers

\subsubsection{Phase 1 / Identification of the Principal Control Center objectives and coherence analysis}

This phase is aiming at identifying the objectives of each Principal Control Center. We follow a top-down approach : it means that the first step consists in identifying the objectives of the Production System, the second in identifying the global objectives of each function belonging to the production axis, and the third in defining the objectives of each Principal Control Center inside each function. These identifications are based on the notion of contribution. Actually, each objective must contribute to the achievement of the objectives identified at a upper level. Each step is supported by graphic tools (splitting up diagrams) allowing to verify if a sub-objective contributes to an objective at a upper level. 
Phase 1.1- Identification of the Production System objectives These objectives come from the Business Planning. They are often expressed in term of optimisation of the triplet Quality / Lead Time / Cost.

Phase 1.2 - Identification of the global objectives for each production axis function and coherence analysis

The same performance criteria (Quality / Lead Time / Cost) appear but more in detail and more specific to the studied function. The global objectives of the production axis functions must contribute to the achievement of the production system objectives (figure 5 ).

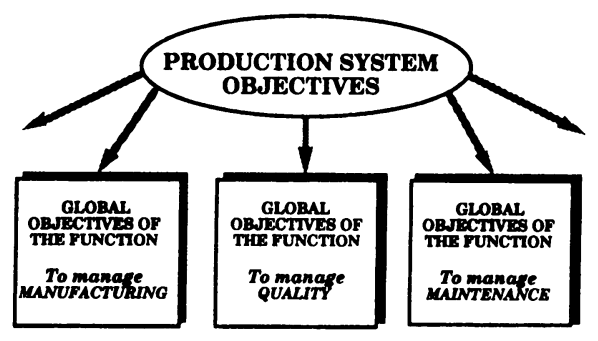

Figure 5. Splitting up of the Production System objectives

To verify these contributions, a splitting up diagrams is used (figure 6).

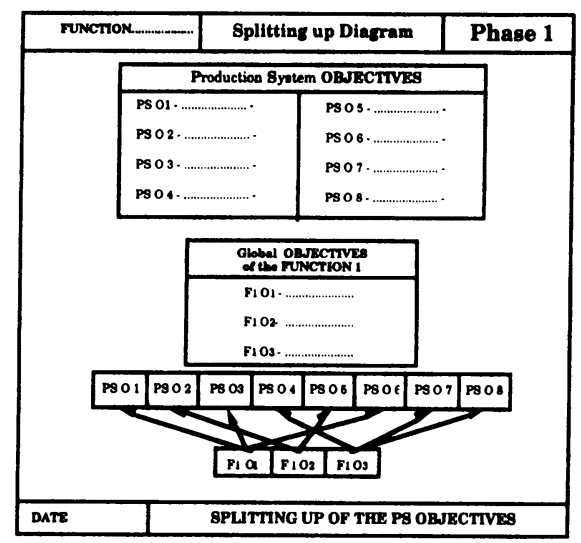

Figure 6. Example of Splitting up diagram

Then, the inter-function coherence between the global objectives is analysed. The links which exist between the global objectives of the various functions are identified in order to check there are no perverse effects (the objectives assigned to a function do not prevent another function to achieve its objectives) (figure 7). 


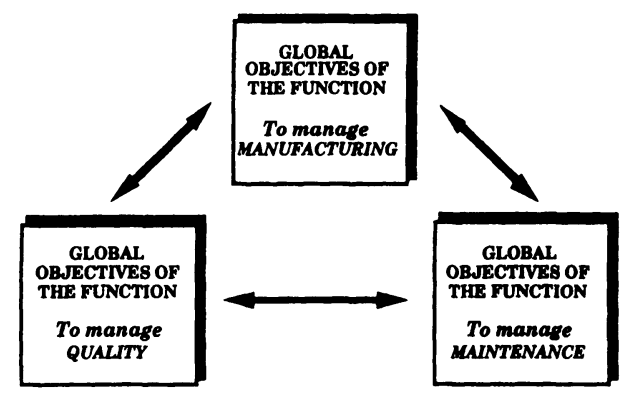

Figure 7. Inter-function coherence analysis between three functions

Phase 1.3 - Identification of the Principal Control Center objectives for each function and intra-function coherence analysis

The last step of the phase 1 consists in identifying the objectives for each Principal Control Centers (figure 8).

This identification is validated by the intra-function coherence study. The principle used is the same : to verify if the objectives of the Principal Control Centers contribute to the achievement of the function global objectives. The same tools as on phase 1.2 are used to show these contributions.

\subsubsection{Phase 2 : Identification of the PCC Drivers and analysis of the conflicts}

As already said, if it is necessary to know the objectives in order to build relevant performance indicators, it is not sufficient. Actually, the drivers, corresponding to each objective of Principal Control Centers must be identified (figure 8). This identification must be interpreted as one of the steps leading to the building of the triplets \{Objectives / Drivers / Performance Indicators\}. This notion of triplet is another valuable characteristic of the method, and it expresses the controllability principle.

During the identification of the DV, it is necessary to put in evidence the intrafunction and inter-function influences of the Drivers. The aim here is to evaluate the relationships which appear into a function and between the functions. Indeed, the proposed objectives (and by consequence the Performance Indicators) for a given Principal Control Center are sometimes related to drivers that belong to other Principal Control Center. In this case, we must evaluate, for the Principal Control Center concerned, the degree and the origin of the influence. The notions of "driver with direct effect and indirect effect" refer to this phenomena. A direct effect is assigned to the driver which has a dominating influence on the considered objective .

\subsubsection{Phase 3 : Identification of the PCC Performance Indicators and internal coherence analysis}

Phase 3.1: Identification of the Performance Indicators for the Principal Control Centers.

The previous phases allow, for each Principal Control Center, to identify one or several objectives (coherent with the global objectives of the function themselves 
coherent with the production system objectives) and the associated drivers. The determination of the Performance indicators is performed during this phase 3 (figure 8). The approach uses the knowledge of all the people involved in the study and this identification is validated by an internal coherence analysis inside each Principal Control Center.

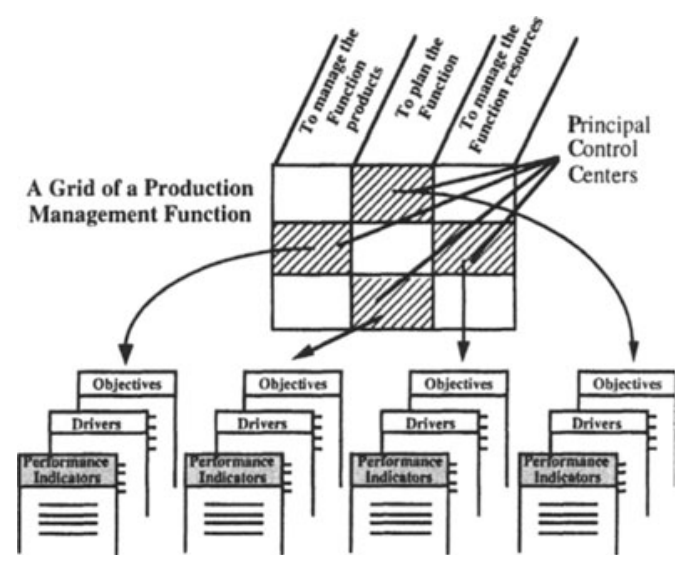

\section{Figure 8. Identification of the PCC Objectives, Drivers, and Performance Indicators}

Phase 3.2 : Internal Coherence Analysis of the PCC

This study consists in verifying the internal coherence inside the Principal Control Center in terms of triplet OObjectives / Drivers / Performance Indicators\}. A triplet is coherent if :

- it is composed of one objective, one or several drivers and one or several performance indicators,

- the performance indicators allow to verify the achievement of the objective, and are influenced by actions on the drivers (figure 9 ).

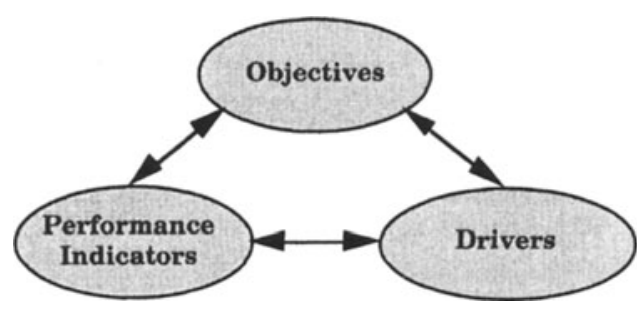

Figure 9. Internal coherence 
In order to verify this coherence, coherence panels are built. They allow to identify the various links between the elements of the PCC as well as their weight.

Then, "coherence panels" are filled in (figure 10). The links between the PCC elements are classified according to the connection (strong link / weak link / no link).

\begin{tabular}{|c|c|c|c|c|c|c|}
\hline \multicolumn{2}{|c|}{ Funetion } & \multicolumn{2}{|c|}{$\begin{array}{c}\text { Decision Cent" } \\
\text { Level }\end{array}$} & \multicolumn{3}{|c|}{ INTERNAL COHERENCE ANALYSI } \\
\hline \multirow{3}{*}{\begin{tabular}{|l|} 
ह \\
\\
\\
\\
\end{tabular}} & 01 & & .. & $*$ & .* & $\cdot$ \\
\hline & 02 & & & $\cdot$ & & $*$ \\
\hline & $\begin{array}{l}\text { PgRYOR } \\
\text { INDICA }\end{array}$ & & IPI & IP 2 & IP: & $1 P 4$ \\
\hline \multirow{3}{*}{$\sum_{8}^{2}$} & Dv & & & - & & .. \\
\hline & ov & & .* & & .. & \\
\hline & Dv & & & . & & . \\
\hline
\end{tabular}

Figure 10. Coherence panel

\subsubsection{Phase 4 : Design of Performance Indicator information system}

An indicator is basically a measure which will become more and more sophisticated : "measure $\rightarrow$ raw information $\rightarrow$ process $\rightarrow$ review $\rightarrow$ statiscal process" can be an example of a possible chain. ECOGRAI is completely oriented towards the phase of specification, which is preliminary to any possible automation of the performance evaluation system. Two aspects are considered : the data aspect (which information is necessary ?) and the processing aspect (the processings which are necessary to build the indicators, starting from basic information). Whatever the case of study, it is always necessary to define clearly each indicator with fundamental parameters. The tool which guides these definitions is the specification sheet for each indicator which contains (figure 11) :

period),

- the identification of the indicator (name, decision center, horizon,

- the objectives and the drivers related to the indicator,

- the perverse effects which have been identified,

the indicator,

- the identification of the data required for the implementation of

- the definition of the associated processings,

- finally, the way of representing the indicator, determined by the future users (using graphics most of the time). 


\begin{tabular}{|c|c|c|}
\hline $\begin{array}{c}\text { ECOGRA } \\
\text { Study }\end{array}$ & 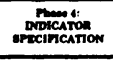 & $\begin{array}{l}\text { Function: } \\
\text { Decision center: } \\
\text { Horizon /Period: } \\
\end{array}$ \\
\hline \multicolumn{3}{|c|}{ Indicator } \\
\hline \multicolumn{3}{|c|}{ Objectives } \\
\hline \multicolumn{3}{|l|}{ Drivers } \\
\hline \multicolumn{3}{|c|}{ Basic Information } \\
\hline \multicolumn{3}{|l|}{ Origin } \\
\hline \multicolumn{3}{|c|}{ Processings } \\
\hline \multicolumn{3}{|c|}{ Required evolution } \\
\hline \multicolumn{3}{|c|}{$\begin{array}{l}\text { Passible perversee effects and possible } \\
\text { repercussions on others indicators }\end{array}$} \\
\hline \multicolumn{3}{|c|}{$\begin{array}{l}\text { Actions to make the indicator evolve in the } \\
\text { required direction }\end{array}$} \\
\hline Deacript & on mode & \\
\hline
\end{tabular}

Figure 11. An example of specification sheet

\subsubsection{Phase 5 : Integration of the Performance Indicator information system in the Production information system}

The phase five consists in integrating the performance measurement system in the production information system. This implementation phase is supported by the use of an EIS tool (EIS : Executive Information System). It is used to converse with the existing data bases. The data on Production information system are located and the extraction frequencies, the processings and the visualisation choice to exploit the Performance Indicator are then specified into the EIS tool. This work is performed from the specification sheet.

\subsection{The implementation of the ECOGRAI method}

One cannot define a method to design and to implement PIS without defining also the way to implement it. So the ECOGRAI structured approach is based on the GRAI structured approach. In particular, the notions of involvement (creation of various working groups), and top-down / bottom-up approach have been kept.

Three kinds of group are defined (figure 12) :

- the project board, is composed of the people in charge of the studied production unit. They define objectives and orientations, and they check the results presented by the analysis group during the project board meetings. They also structure the information and locate them in their context,

- the synthesis group, is composed of the person in charge of each studied function of the production system, of the supervisors, and if necessary, of the operators. During the synthesis meetings with the analysis group, this group is involved in the organisation analysis of the function they are in charge of, and in the definition of the indicators,

- the analysis group, composed of an analyst and of a person in charge of the considered production unit. This group is in charge of ensuring the operational part of the study. They organize meetings and collect information. 
They also formalize the results, and propose solutions to the problems which may appear during the study.

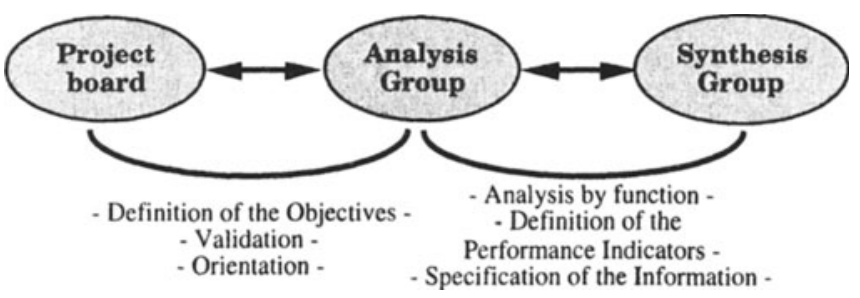

Figure 12. The various groups involved in the structured approach

The information technology department involved in the design, with the help of an EIS specialist, ensures the physical implementation of the performance indicators.

Thus, after having constituted the various groups, the structured approach follows the six phases of the method. The main remark which can be made is the continuous iteration between the synthesis group and the project board all along the study.

\section{EXAMPLE OF ECOGRAI APPLICATION TO THE MAINTENANCE FUNCTION}

ECOGRAI can be applied on all the production functions (Engineering, Manufacturing, Quality, Maintenance, delivery...) with a global approach or more specifically on only one function. This paragraph is aiming at presenting the results of the ECOGRAI method application on a specific function of a production system : the Maintenance function.

3.1 Results of the phase 0 : "Modelling of the Maintenance control structure and identification of the PCC"

The GRAI grid presented below (figure 13) models the maintenance control structure. The grey tint decision center correspond to the identified PCC.

Indeed, nine Principal Control Centers have been identified inside this grid. They correspond to the decision centers who have a principal influence on the maintenance control system. 


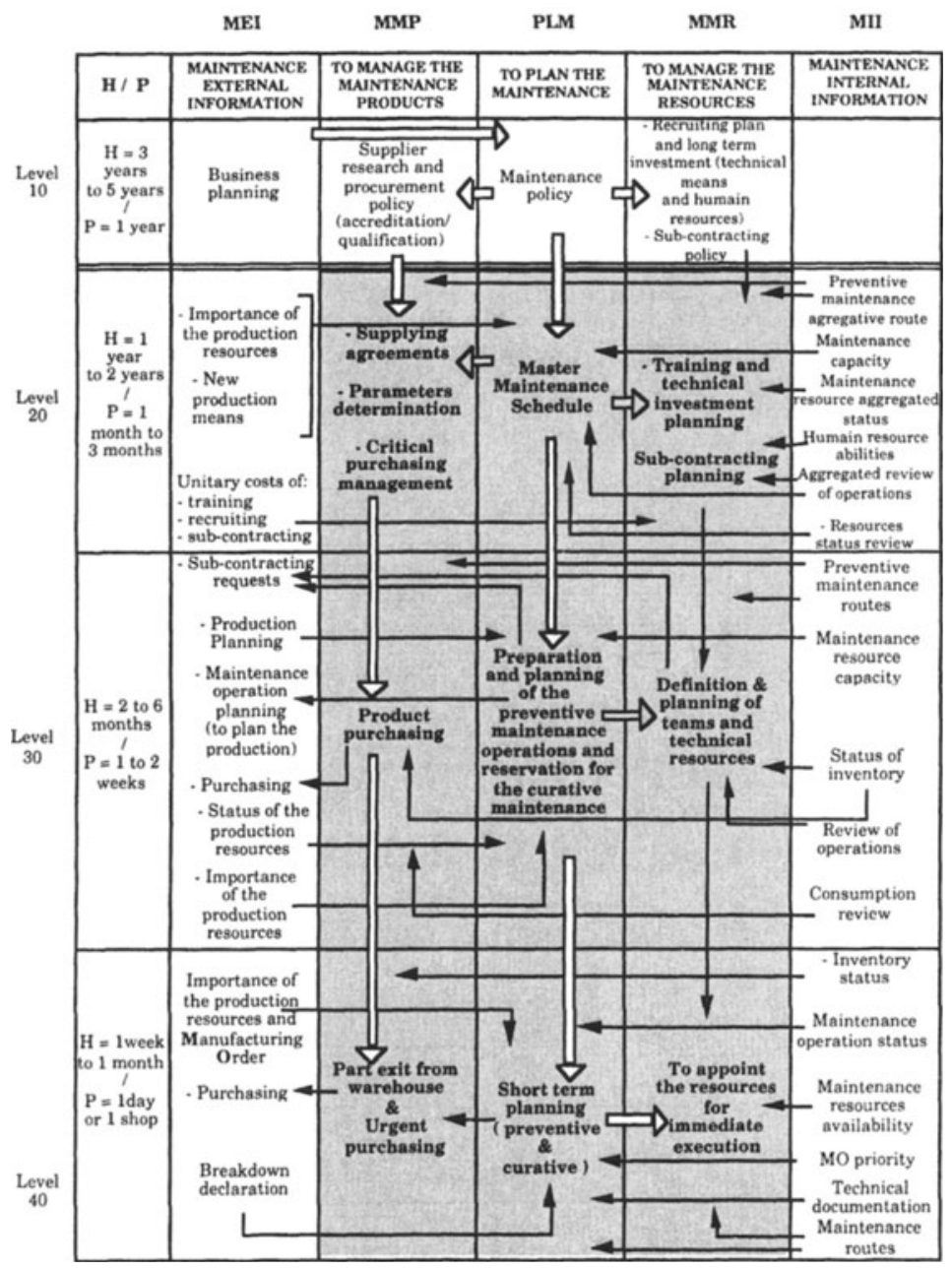

Figure 13. GRAI grid of the Maintenance function

\subsection{Results of the phase 1 : "Identification of the Principal Control Center Objectives and coherence analysis"}

\subsubsection{Results of the phase 1.1 "Identification of the Production System Objectives"}

According to the triplet $\{$ Quality, Lead time, Cost\} (Q, Lt, C), three Production System Objectives $\left(P S O_{n}\right)$ have been identified :

$\mathrm{PS} \mathrm{O}_{1}$ : To respect the required Quality level 
$\mathrm{PS}_{2}$ : To respect the production Lead time

$\mathrm{PS}_{3}$ : To minimize the production Costs

3.2.2 Results of the phase 1.2 "Identification of the Maintenance Global Objectives and coherence analysis"

Three global Maintenance function Objectives $\left(\mathrm{M}_{\mathrm{F}} \mathrm{O}_{\mathrm{n}}\right)$ have been identified :

$\mathrm{MF}_{\mathrm{F}} \mathrm{O}_{1}$ : To maximize the Maintenance operation Quality

$\mathrm{M}_{\mathrm{F}} \mathrm{O}_{2}$ : Maximal availability of production resources

$\mathrm{M}_{\mathrm{F}} \mathrm{O}_{3}$ : To minimize the maintenance Costs

In order to analyse the coherence between the Production System objectives and those of Maintenance function, the following splitting up diagram is used (figure 14):

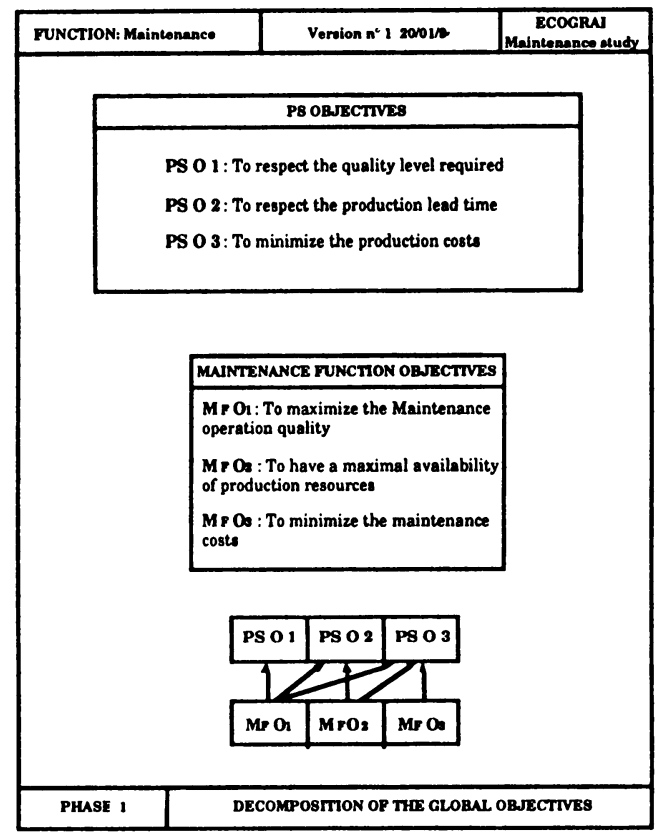

Figure 14. Splitting up diagram of the maintenance function $\left(M_{F}\right)$

3.2.3 Results of the phase 1.3 "Identification of the PCC Objectives and coherence analysis"

In order to have an explicit presentation and to avoid redundancies in the explanations, we present only one Principal Control Center. We have chosen PLM 20: function "To plan the Maintenance" (PLM) Level 20, because it determines the Master Maintenance Schedule.

Master Maintenance Schedule : Function "To plan the Maintenance" (PLM) Level 20

Activity : To plan the Maintenance activities by resource sub-set (team, specialist...)

Objectives : - PLM $20 \mathrm{O}_{1}$ : To optimize the appropriateness maintenance load / maintenance internal capacity. 
- PLM $20 \mathrm{O}_{2}$ : To minimize the maintenance cost for an equal availability.

This decision center receives its decision frame from the PLM 10 decision center. The PLM 10 objectives are in fact the same as the global objectives of the Maintenance function.

Then, in order to analyze the coherence between the PLM 20 objectives and the PLM 10 objectives, the following splitting up diagram is used (figure 15) :

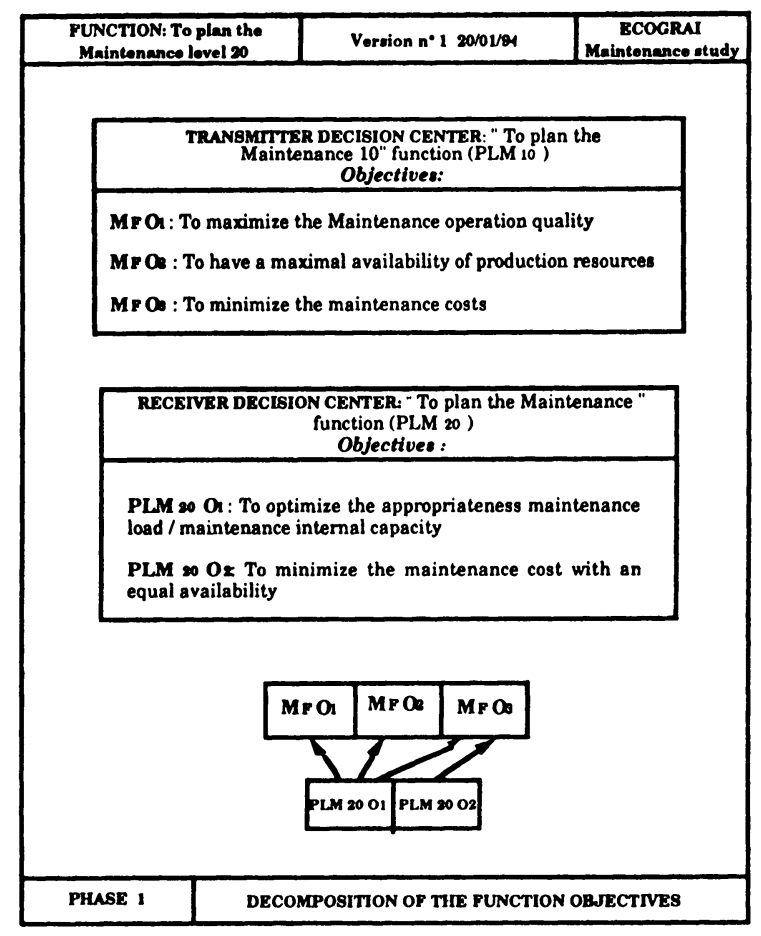

Figure 15. Splitting up diagram of PLM 20

\subsection{Results of the phase 2 : " Identification of the Principal Control Center Drivers and analysis of the conflicts"}

We can remind here that the Decision variables are the variables on which the decision makers can act in order to reach the objectives. So, according to the PLM 20 objectives, the following Drivers have been identified :

- PLM $20 \mathrm{DV}_{1}$ : Choice of the maintenance type (preventive, predictive or curative ) ratio by resource sub-net.

- PLM $20 \mathrm{DV}_{2}$ : Maintenance activity priority.

The analysis of the conflicts has been performed between the various PCC of the maintenance function. In this example, we have not found conflicts between the various Drivers. 


\subsection{Results of the phase 3 : "Identification of the Principal Control Center Performance Indicators and internal coherence analysis"}

\subsubsection{Results of the phase 3.1 "Identification of the PCC Performance Indicators"}

We can remind here that the Performance Indicators allow to the decision makers to measure the achievement of the objectives and that they are influenced by actions on the previous drivers. So, according to the PLM 20 objectives and drivers, the following Performance Indicators have been defined:

- PLM $20 \mathrm{PI}_{1}$ : Maintenance internal capacity use rate,

- PLM $20 \mathrm{PI}_{2}$ : Maintenance cost (salary + training + investments + parts

+ inventories + sub-contracting + infrastructure).

3.4.2 Results of the phase 3 (2) "Internal coherence analysis"

The internal coherence analysis is performed in filling in the coherence panel of the PCC. This panel is presented below (figure 16) :

\begin{tabular}{|c|c|c|c|c|c|}
\hline \multicolumn{2}{|c|}{$\begin{array}{c}\text { Function } \\
\text { Maintenance }\end{array}$} & \multicolumn{2}{|c|}{$\begin{array}{l}\text { Decision Center: PLM } \\
\text { Level: } 20\end{array}$} & \multicolumn{2}{|c|}{$\begin{array}{l}\text { INTERNAL COHERENCE } \\
\text { ANALYSIS }\end{array}$} \\
\hline \multirow{3}{*}{ 畩 } & \multicolumn{2}{|c|}{$\begin{array}{l}\text { O1: To optimize the } \\
\text { appropriateness maintenance load / } \\
\text { maintenance internal capacity }\end{array}$} & & $*$ & \\
\hline & \multicolumn{2}{|c|}{$\begin{array}{l}\mathrm{O} 2 \text { : To minimize the maintenanc } \\
\text { cost with an equal availability }\end{array}$} & & * & $*$ \\
\hline & \multicolumn{2}{|c|}{$\begin{array}{l}\text { PERFORMANCE } \\
\text { INDICATORS }\end{array}$} & $\begin{array}{r}N \\
\text { inte }\end{array}$ & $\begin{array}{l}\text { PI 1 } \\
\text { aintenance } \\
\text { rnal capacity } \\
\text { use rate }\end{array}$ & $\begin{array}{c}\text { PI } 2 \\
\text { Maintenance cost }\end{array}$ \\
\hline \multirow{2}{*}{ 造 } & \multicolumn{2}{|c|}{$\begin{array}{l}\text { DV 1: Choice of the maintenance } \\
\text { type (preventive, predictive o1 } \\
\text { curative) ratio by resource sub-set }\end{array}$} & & $*$ & $*$ \\
\hline & \multicolumn{2}{|c|}{$\begin{array}{l}\text { DV } 2 \text { : Maintenance activity } \\
\text { priority }\end{array}$} & & $*$ & * \\
\hline
\end{tabular}

Strong link (**) / Weak link $\left(^{*}\right) /$ No link ( )

\section{Figure 16. Coherence panel of PLM 20}

Regarding to this panel, we can see :

- that each Objective is connected at least to one PI and one DV,

- that each DV is connected at least to one Objective and one PI,

- that each PI is connected at least to one objective and one DV.

So, this decision center is coherent inside.

The GRAI net built from all the results is presented below (figure 17). It describes the PLM 20 decisional activity, the involvement of each support, defined in the GRAI grid and in the previous results (information, constraints, 
objectives, drivers, performance indicators), in the decision making and the final result of this PCC.

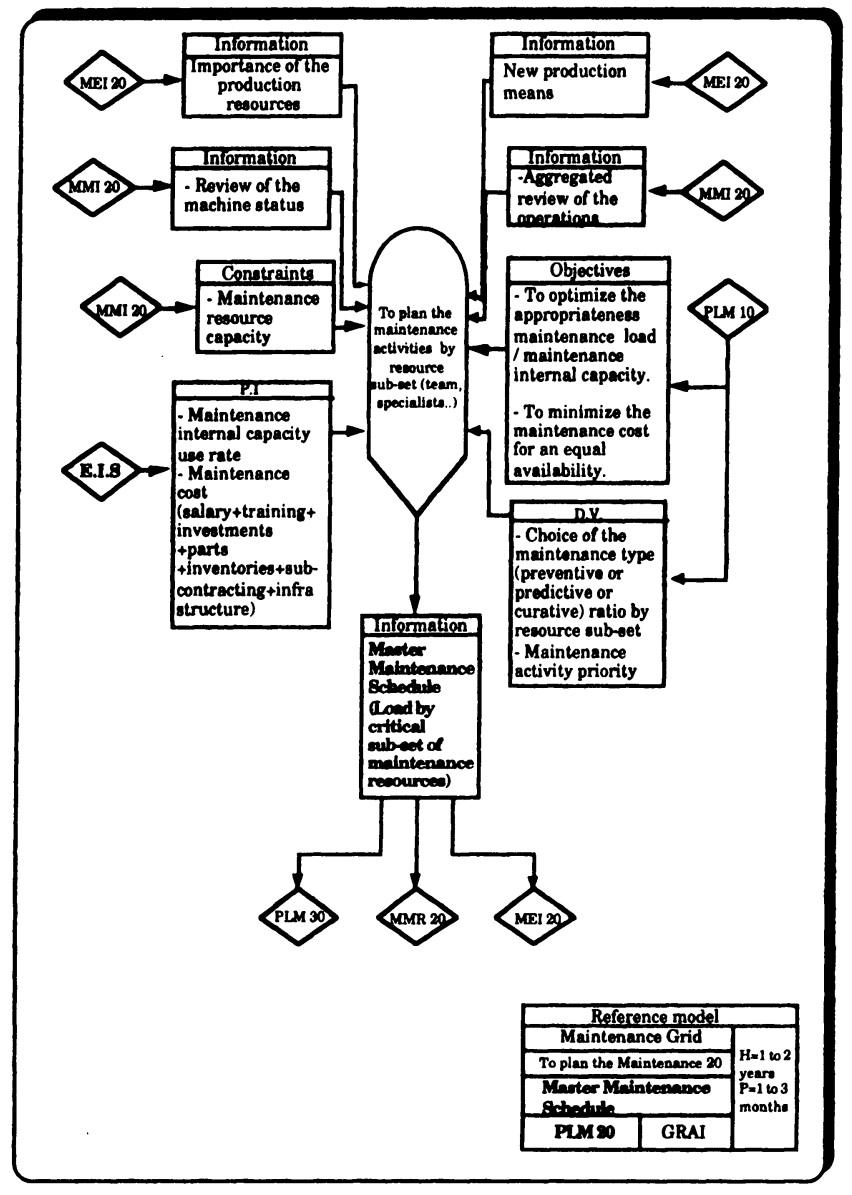

Figure 17. PLM 20 GRAI net

\subsection{Results of the phase 4 : "Design of the PI information system"}

This phase consists in building the specification sheet of each PI. The specification sheet of the PI "Maintenance internal capacity use rate" is presented below (figure 18) : 


\begin{tabular}{|c|c|c|}
\hline $\begin{array}{l}\text { ECOGRAI } \\
\text { Study }\end{array}$ & $\begin{array}{l}\text { Phang } \\
\text { IIDICATOR } \\
\text { BPECICACATION }\end{array}$ & 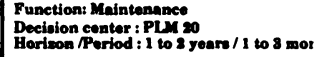 \\
\hline \multicolumn{3}{|c|}{ Indicator:Maintenance internal capacity une rate } \\
\hline \multicolumn{3}{|c|}{$\begin{array}{l}\text { Objectives } \\
\text { - To optimize the appropriateness maintenance load } \\
\text { maintenance internal capacity }+* \\
\text { - To minimize the maintenance cont with an equal availability }\end{array}$} \\
\hline \multicolumn{3}{|c|}{$\begin{array}{l}\text { Drivers } \\
\text { - Choice of the maintenance type (preventive, predictive or } \\
\text { curative) ratio by resource oub-eet " } \\
\text { - Maintenance activity priority " }\end{array}$} \\
\hline \multicolumn{3}{|c|}{$\begin{array}{l}\text { Basic Information } \\
\text { - Total maintenance internal capacity (in hourn) } \\
\text { - Total used capacity }\end{array}$} \\
\hline \multicolumn{3}{|c|}{ Origin : Data base of each resource } \\
\hline \multicolumn{3}{|c|}{$\begin{array}{l}\text { Processings : By dividing the total used capacity by the total } \\
\text { maintenance capacity }\end{array}$} \\
\hline \multicolumn{3}{|c|}{ Required evolution : Equal to 1} \\
\hline \multicolumn{3}{|c|}{$\begin{array}{l}\text { Possible perverse effects and possible repercussions } \\
\text { on other indicators }\end{array}$} \\
\hline \multicolumn{3}{|c|}{$\begin{array}{l}\text { Actions to make the indicator evolve in the } \\
\text { required direction } \\
\text { To increase the preventive and predictive maintenance ration } \\
\text { during the under-load periods }\end{array}$} \\
\hline $8 \mathrm{cr}$ & e : & \\
\hline
\end{tabular}

Figure 18. Specification sheet of the PI "Maintenance internal capacity use rate"

3.6 Results of the phase 5 : "Integration of the PI information system in the maintenance information system"

This phase consists of implementing the concerned PI in the Maintenance information system.

The visualization of the previous PI from the EIS tool is presented below (figure 19) :

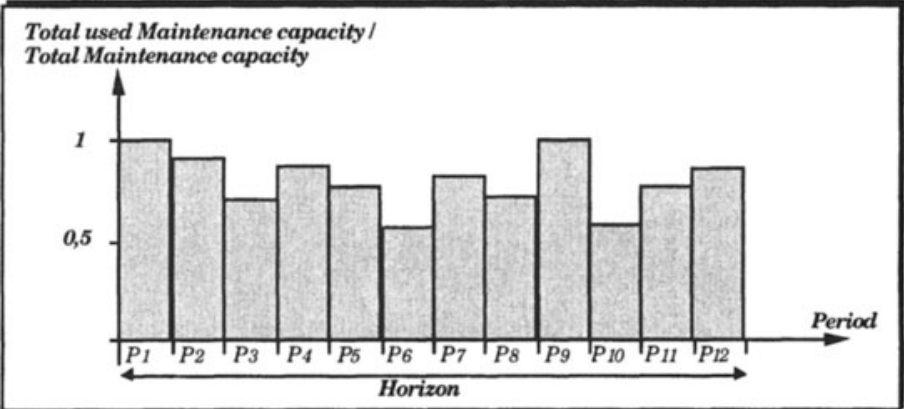

Figure 19. PI visualization 


\section{CONCLUSION}

This application allows to illustrate the various possibilities of ECOGRAI method to design and to implement Performance Measurement Systems. The original approach, including a participative demarch, assures a real involvement of the future users. Actually, many methods proceed with the following way : Objectives --> Performance Indicators, whereas ECOGRAI uses with a different approach : Objectives --> Drivers --> Performance Indicators. This original approach allows also to identify relevant PI. Thus, it reduces the number of PI with improving efficiency and performance measurement system adoption.

This model was used in the IMS Project Globeman 21 as a basic concept to elaborate Matrix in order to benchmark industrial practices.

At this time, the works on ECOGRAI are oriented towards software tool developments, to support the method application on the one hand (linked with the CAGIM software : Computer Aided Grai Integrated Methodology) and on the other hand to support the Performance Indicator System implementation (EIS).

\section{BIBLIOGRAPHY}

ANCELIN B., (1989), "Quels critères de performance pour les nouveaux ateliers", Revue Française de Gestion Industrielle, $N^{\circ} 1,1989$, pp. 66-84.

BERADA M., (1992), "Mise en place des tableaux de bord à la SAPSO", ADEPA, Rapport interne au GRAI.

BITTON M., (1990), "Méthode de conception et d'implantation de systèmes de mesures de performances pour organisations industrielles", Thèse d'automatique, Université de Bordeaux I, 220 pages.

BITTON M., DOUMEINGTS G., (1990), "Conception de systèmes de mesures de performances : la méthode ECOGRAI", ECOSIP, "Gestion industrielle et mesure économique, approches et applications nouvelles", Economica, pp. 251-274.

DOUMEINGTS G.,(1984), "Méthode GRAI, méthode de conception des systèmes en productique", Thèse d'état es-Sciences, Université de Bordeaux I.

DOUMEINGTS G. , CLAVE F. (1993), "Méthode pour concevoir et implanter un système d'indicateurs de performances en production - Concepts et exemples d'application -", CETIM, "Mieux gérer la production : les outils économiques d'aujourd'hui".

EVRAERT S., MEVELLEC P., (1990), "Calcul des coûts : il faut dépasser les méthodes traditionnelles", Revue Française de gestion, Mars-Avril-Mai 1990, $N^{\circ} 78$, pp. 12-24.

FRAY C., GIARD V., SYBORD T., (1988), "Méthodologie d'analyse et d'évaluation économique des décisions en production", Communication aux journées "Productique" de l'AFCET, 20 Juin 1988, 21 pages. 
GIARD V., (1988), "Evaluation économique et prise de décision en gestion de production", Revue Française de Gestion, N 67, Janv-Fév 1988.

GRADY M., (1991), "Performance measurement : implementing strategy", Management Accounting, June 1991, pp. 49-53.

GREENE A., FLENTOV P., (1990), "Managing performance : maximizing the benefit of Activity-Based Costing", Journal of Cost Management, Summer 1990, pp. 51-59.

KAPLAN R., JONHSON T., (1990), "Relevance lost : The rise and fall of management accounting", Harvard Business School Press, Boston, Massachussets.

LORINO P., (1991), "Le contrôle de gestion stratégique", la gestion par les activités", Dunod Entreprise, 230 pages. 